\title{
A RESPONSABILIDADE CIVIL DOS PRINCIPAIS CLOUD COMPUTING PROVIDERS EM RAZÃO DA PERDA DE ARQUIVOS
}

\section{THE CIVIL LIABILITY OF THE MAIN CLOUD COMPUTING PROVIDERS RESULTING FROM LOSS OF FILES}

\author{
Rosane Leal da Silva \\ Universidade Federal de Santa Maria - UFSM - (Santa Maria, RS, Brasil) \\ Rafaela Bolson Dalla Favera \\ Universidade Federal de Santa Maria - UFSM - (Santa Maria, RS, Brasil) \\ Olívia Martins de Quadros Olmos \\ Universidade Franciscana - UFN - (Santa Maria, RS, Brasil)
}

Recebimento: 29 mar. 2018

Aceitação: 23 maio 2018

\begin{abstract}
Como citar este artigo / How to cite this article (informe a data atual de acesso / inform the current date of access):
SILVA, Rosane Leal da; FAVERA, Rafaela Bolson Dalla; OLMOS, Olívia Martins de Quadros. A responsabilidade civil dos principais cloud computing providers em razão da perda de arquivos. Revista da Faculdade de Direito UFPR, Curitiba, PR, Brasil, v. 63, n. 2, p. 89-113, ago. 2018. ISSN 2236-7284. Disponível em: $<$ https://revistas.ufpr.br/direito/article/view/58628>. $\quad$ Acesso $\quad$ em: $30 \quad$ ago. $2018 . \quad$ DOI: http://dx.doi.org/10.5380/rfdufpr.v63i2.58628.
\end{abstract}

\section{RESUMO}

O presente trabalho tem por escopo discutir o sistema de responsabilidade civil, em caso de extravio de arquivos dos principais cloud computing providers existentes. O problema de pesquisa que se buscou responder ao longo desse artigo foi: é possível afirmar que o sistema de responsabilidade civil brasileiro é adequado e suficiente para a tutela dos titulares dos dados armazenados em nuvem? Para tal estudo, utilizou-se o método de abordagem dedutivo, visto que a pesquisa partiu de uma análise geral dos provedores de computação em nuvem, para, em seguida, tratar especificamente da questão da responsabilidade civil. Já quanto ao método de procedimento, empregou-se o comparativo, pois foram estudados os termos de privacidade e uso de três provedores com a finalidade de identificar sua relação. Por fim, foram adotadas técnicas de pesquisa documental e bibliográfica. Constatou-se que a legislação aplicável diante da perda ou extravio de arquivos desses provedores é o Código de Defesa do Consumidor, pois a relação existente entre os provedores de computação em nuvem e os usuários/consumidores é uma relação de consumo, havendo, portanto, responsabilidade objetiva.

\section{PALAVRAS-CHAVE}

Computação em nuvem. Direito do consumidor. Novas tecnologias. Provedores. Responsabilidade civil.

\begin{abstract}
The purpose of this paper is to discuss the civil liability system in case of loss of files from the main cloud computing providers. The research problem that was sought to answer throughout this paper was: Is it possible to assert that the Brazilian civil liability system is adequate and sufficient for the
\end{abstract}


protection of the holders of data stored in the cloud? For this study, the deductive method of approach was used, since the research was based on a general analysis of the cloud computing providers, and then specifically deal with the issue of civil liability. Regarding the procedure method, the comparative one was used, since the terms of privacy and use of three providers were studied in order to identify their relationship. Finally, the techniques of documentary and bibliographic research were adopted. It was concluded that the applicable legislation regarding the loss of files from these providers is the Consumer Protection Code, since the relationship between cloud providers and users/consumers is a consumption one, therefore implying an objective liability.

\section{KEYWORDS}

Cloud computing. Consumer law. New technologies. Providers. Civil liability.

\section{INTRODUÇÃO}

O progressivo desenvolvimento ou aprimoramento de novas tecnologias não é mais novidade. O surgimento de modernos aparatos tecnológicos é constante e, por vezes, previsível em função das necessidades e exigências da sociedade. A cloud computing, ou computação em nuvem, por exemplo, passou a ser utilizada por pessoas físicas e jurídicas muito rapidamente, em função das facilidades advindas do seu emprego, embora as empresas tenham se apoderado desse recurso por ser, eventualmente, mais benéfico aos seus negócios.

Contudo, os indivíduos também se beneficiam da computação em nuvem de diversas formas, pois o usuário pode se deslocar fisicamente sem a necessidade de levar consigo um pen drive ou um HD externo com conteúdo. Basta colocá-lo na nuvem para poder acessá-lo de qualquer celular, notebook, computador ou outro dispositivo conectado à Internet. Além disso, a nuvem permite que esse conteúdo seja editado e salvo. Assim, quando for aberto em outro equipamento estará atualizado. Essa é uma das grandes facilidades que a computação em nuvem proporciona.

Porém, a nuvem está longe de ser um ambiente seguro, como afirmam as empresas do ramo, pois os estudiosos da área de Tecnologia da Informação (TI) ensinam que nenhum ambiente on-line e, por vezes, off-line, está totalmente livre do ataque de hackers e crackers ou até mesmo de defeitos que levam à perda de arquivos. Nesse contexto, a função do Direito é encontrar soluções para os problemas que emergem da utilização desses serviços.

Assim, tendo em vista os contratos de adesão firmados entre os principais cloud computing providers existentes, quais sejam, GoogleDrive, OneDrive e Dropbox, e os usuários/consumidores pessoas físicas, em conjunto com a legislação e a doutrina brasileira, questiona-se: é possível afirmar que o sistema de responsabilidade civil brasileiro é adequado e suficiente para a tutela dos titulares dos dados armazenados em nuvem? 
Para responder a essa indagação, utilizou-se o método de abordagem dedutivo, tendo em vista que a pesquisa partiu de uma análise geral dos provedores de computação em nuvem e dos serviços ofertados, para, após, tratar especificamente da questão da responsabilidade civil. Já quanto ao método de procedimento, empregou-se o comparativo, pois foram estudados os termos dos três provedores objeto de análise com a finalidade de identificar sua relação. Por fim, como técnicas de pesquisa adotaram-se a documental e a bibliográfica.

Diante desse aporte metodológico, o artigo restou dividido em duas seções, sendo que na primeira foi apresentado e conceituado o que se entende por provedores de computação em nuvem. Já na segunda, dividida em três subseções, foram, em um primeiro momento, expostos os termos dos provedores GoogleDrive, OneDrive e Dropbox. A seguir, foram exploradas questões relevantes a respeito dos contratos eletrônicos e, por fim, na última subseção, foi enfrentado o tema da responsabilidade civil nesse contexto.

\section{CLOUD COMPUTING PROVIDERS: SITUANDO A DISCUSSÃO, A PARTIR DE CONCEITOS}

A computação em nuvem se tornou um tema muito discutido nos últimos tempos e a compreensão de seu desenvolvimento exige, preliminarmente, que sejam expostas algumas noções, ainda que básicas, sobre a Internet, o que será feito não somente para situar a matéria, mas também para evidenciar os avanços produzidos, num curto espaço de tempo, nesse segmento.

As origens da Internet, de acordo com Castells (2001, p. 13), podem ser encontradas na Arpanet, que foi uma rede de computadores criada pela Advanced Research Projects Agency (ARPA), em setembro de 1969. Leonardi (2005, p. 3) expõe que o objetivo do programa Arpanet era "possibilitar a comunicação e a transferência de dados entre seus usuários através de canais redundantes, de forma a garantir o funcionamento do sistema mesmo na hipótese de destruição de partes da rede em uma eventual guerra”.

A ascensão da Internet, segundo Paesani (2006, p. 25), ocorreu no ano de 1973, quando foi registrado o Protocolo de Controle da Transmissão / Protocolo Internet, por Vinton Cerf - responsável pelo projeto. Para a autora, "trata-se de um código que consente aos diversos networks incompatíveis por programas e sistemas comunicarem-se entre si”.

Castells (2001, p. 18) aponta que foi a partir do software Enquire, desenvolvido por BernersLee, que foi produzida a World Wide Web, que pode ser entendida como um sistema de hipertexto no qual informações poderiam ser acrescentadas pelos usuários e acessadas por computadores que 
estivessem conectados à rede. Em seguida, conforme exposto pelo referido autor, foram introduzidas novas versões do software - a Netscape Communications disponibilizou, em outubro de 1994, o primeiro navegador comercial, denominado Netscape Navigator.

Conforme Castells (2001, p. 19), após o sucesso do Navigator, “a Microsoft finalmente descobriu a Internet, e em 1995, junto com seu software Windows 95, introduziu seu próprio navegador, o Internet Explorer”. A Internet, segundo o doutrinador, surge na metade da década de 1990 como um sistema de comunicação flexível e descentralizado. Para ele, essa flexibilidade e a liberdade foram valores importantes para o desenvolvimento da rede mundial de computadores.

Leonardi (2005, p. 1) define Internet "como uma rede internacional de computadores conectados entre si” e considera que essa “é hoje um meio de comunicação que possibilita o intercâmbio de informações de toda natureza, em escala global, com um nível de interatividade jamais visto anteriormente”.

Na mesma senda, Castells (2001, p. 7) entende que a Internet é uma tecnologia que permite, pela primeira vez, “a comunicação de muitos com muitos, num momento escolhido, em escala global” e, por isso, sua utilização transforma o modo como as pessoas interagem social, econômica e politicamente. O autor destaca, também, que ela “é o tecido de nossas vidas”. Para ele,

[...] se a tecnologia da informação é hoje o que a eletricidade foi na Era Industrial, em nossa época a Internet poderia ser equiparada tanto a uma rede elétrica quanto ao motor elétrico, em razão de sua capacidade de distribuir a força da informação por todo o domínio da atividade humana.

Paesani (2006, p. 25) expõe que a Internet é vista “como um meio de comunicação que interliga dezenas de milhões de computadores no mundo inteiro e permite o acesso a uma quantidade de informações praticamente inesgotáveis, anulando toda distância de lugar e tempo”. Cria-se, portanto, um tempo atemporal e um espaço de fluxos, conforme ensinado por Castells (2013, p. 70).

Assim, verifica-se, a partir das citações, que esse meio de comunicação possibilita a consolidação da sociedade tecnológica e, além disso, permite que as pessoas busquem informações e que interajam, independentemente da distância. Para permitir maior êxito na realização dessas operações, novos aplicativos e plataformas são incessantemente desenvolvidos e lançados, a evidenciar um mercado dinâmico e com renovada capacidade de criação.

Em meio a toda essa expansão surge a computação em nuvem, sistema novo de armazenamento que tem despertado muito interesse em usuários privados e empresas. De acordo com Viggiani e Vellasco (2014), esse termo vem sendo refletido desde o início da Internet, no fim da década de 60, com Joseph Carl, um dos desenvolvedores da Arpanet. Porém, conforme os autores 
mencionados, a expressão computação em nuvem foi citada pela primeira vez no ano de 1997, em uma palestra ministrada pelo professor do Curso de Sistemas de Informação Ramnath Chellappa, mas foi realmente desenvolvida a partir de 1999.

Na visão de Viggiani e Vellasco (2014, p. 425), “a cloud computing representa uma mudança de paradigma no fornecimento de serviços computacionais, atualizando a maneira como serviços de Tecnologia da Informação (TI) são inventados, desenvolvidos e até vendidos”.

Segundo Velte, Velte e Elsenpeter (2012, p. 4), “a computação em nuvem é uma ideia que nos permite utilizar as mais variadas aplicações via internet, em qualquer lugar e independente da plataforma, com a mesma facilidade de tê-las instaladas em nosso próprio computador; mais frequentemente, este será um data center remoto”. Para eles, a computação em nuvem traz muitos benefícios, como a minimização dos custos dos servidores, o poder de controlar as atualizações de software e a possibilidade de pagar menos pelo serviço, dependendo do contrato.

Nessa senda, Velte, Velte e Elsenpeter (2012, p. 3) consideram, também, que a função da computação em nuvem é “cortar custos operacionais e, o mais importante, permitir que departamentos de TI se concentrem em projetos estratégicos em vez de manter o data center funcionando”.

Conforme pesquisa realizada no site Globo Tecnologias (CLOUD..., 2015),

Cloud Computing é um termo em evolução que descreve o desenvolvimento de muitas das tecnologias e abordagens existentes em computação para algo distinto. A nuvem separa as aplicações e os recursos de informação de sua infraestrutura básica. A nuvem realça a colaboração, agilidade, escalabilidade e disponibilidade, e oferece o potencial para redução de custos através de computação eficiente e optimizada. Mais especificamente, a nuvem descreve o uso de uma coleção de serviços, aplicações, informação e infraestrutura composta por pools de recursos computacionais, de rede, de informação e de armazenamento.

A partir desse conceito, ao que se somam as contribuições doutrinárias já anteriormente expostas, pode-se considerar que esse novo modelo de serviço disponível na Internet traz inúmeros benefícios e vantagens para as pessoas. Com o auxílio dessa tecnologia os usuários podem facilmente ver, manipular e compartilhar dados, o que economiza tempo e reduz distâncias, efetivando um verdadeiro espaço de fluxos (VELTE; VELTE; ELSENPETER, 2012).

Para Shaw (2013, p. 2), a computação em nuvem possui as seguintes características: “ondemand self-service, broad network access, rapid elasticity, resource pooling, measurement service”1. Isso permite que os conteúdos sejam acessados de qualquer lugar, a qualquer hora e por meio dos mais diversos tipos de dispositivos, ao que se agrega serviço de monitoramento disponível aos usuários.

\footnotetext{
${ }^{1}$ Em tradução livre: "autoatendimento sob demanda, acesso amplo à rede, elasticidade rápida, agrupamento de recursos, serviço de medição”.
} 
Na concepção da autora Menken (2008, p. 8-9),

Cloud computing is a style of computing in which dynamically scalable and often virtualized resources are provided as a service over the Internet. [...] Users need only be concerned with their terminal and Internet connection, so they can access the tools that the cloud can provide ${ }^{2}$.

Ao tratarem das potencialidades desse serviço, Marques e Crespo (2015, p. 132-133) descrevem os três principais modelos de serviço, quais sejam: 1) Infraestrutura como Serviço (IaaS); 2) Plataforma como Serviço (PaaS); e 3) Software como Serviço (SaaS). O primeiro diz respeito "ao fornecimento da infraestrutura computacional como um serviço”, ou seja, refere-se à contratação de um serviço dentro de um data center. O segundo modelo (PaaS) está ligado ao “oferecimento de uma plataforma de desenvolvimento de aplicações (inclusive de software) como um serviço”. E, por fim, o último modelo relaciona-se ao "uso de aplicações sob demanda, tais como aplicativos de escritório na web, serviços de correio eletrônico, agenda, entre outros”.

Existem várias espécies de nuvens, como: 1) Privada, pertencente única e exclusivamente à empresa adquirente, para as finalidades de seu próprio negócio, possuindo um custo mais elevado; 2) Pública, mais conhecida por estar disponível na Internet para o uso do público em geral e, também, pelo baixo custo; 3) Comunitária, que envolve a união de várias empresas em uma só nuvem, a fim de dividirem os custos de infraestrutura; e 4) Híbrida, relacionada à utilização de mais de um modelo, variando a espécie de nuvem em prol da segurança e das exigências legais (MARQUES; CRESPO, 2015, p. 136).

Destarte, pode-se entender que a computação em nuvem é um serviço oferecido pela Internet, no qual o usuário (pessoa física ou jurídica) contrata com o provedor para ter direito de acesso ao conteúdo armazenado por ele em nuvem, constituindo-se função do prestador de serviço (provedor que armazena as informações) atentar para a segurança dos dados custodiados. Ademais, o provedor contratado deve fornecer serviços como armazenamento, backup de conteúdo, processamento, entre outros. Os usuários, assim, podem ter acesso de forma teoricamente segura aos seus dados de qualquer lugar e a qualquer tempo.

A par de todas as vantagens, as tecnologias, sobretudo as novas, também revelam riscos. No caso em estudo, a preocupação repousa na segurança dos arquivos contra ataques de terceiros e até mesmo ante o risco de perda de conteúdo. No ano de 2013, por exemplo, o ex-técnico da Agência de Inteligência e Segurança dos Estados Unidos - NSA -, Edward Snowden, revelou que uma vasta

\footnotetext{
${ }^{2}$ Em tradução livre: “Computação em nuvem é um estilo de computação, no qual os recursos dinamicamente escaláveis e muitas vezes virtualizados são fornecidos como um serviço por meio da Internet. [...] Os usuários só precisam se preocupar com o seu terminal e conexão à Internet, para que então possam acessar as ferramentas que a nuvem pode proporcionar.”
} 
quantidade de dados e informações estava sendo coletada diretamente de servidores de computação em nuvem, especialmente da Microsoft, para serem armazenadas e analisadas pelo governo, sem autorização judicial ou ilegalmente (GREENWALD, 2014, p. 120).

Diante desses riscos, faz-se necessário discutir o sistema de responsabilidade civil brasileiro, para identificar se ele permite tutelar de maneira adequada e suficiente os dados dos usuários, tema que será abordado na sequência.

\section{RESPONSABILIDADE CIVIL DOS PROVEDORES EM FACE DO EXTRAVIO DE ARQUIVOS ARMAZENADOS EM NUVEM}

O armazenamento de conteúdos em nuvem vem crescendo no Brasil, segundo dados obtidos pela Growth from Knowledge (GfK), uma empresa alemã especializada, desde 1934, em pesquisa de mercado. Segundo apurado em levantamento recente, os usuários brasileiros consideram essencial o acesso ou armazenamento em nuvem, o que coloca o País em segunda posição, entre vinte e dois países investigados, só perdendo para o México, considerado “líder mundial da nuvem” (AQUINO, 2015).

Tais dados evidenciam que os brasileiros estão aderindo cada vez mais às Tecnologias da Informação e Comunicação (TIC), e buscam novidades aliadas à praticidade, como a computação em nuvem. Para dar conta dessa demanda crescente existem inúmeros cloud computing providers no mercado nacional e internacional, com destaque para os principais que, segundo Higa (2016), são considerados pelos consumidores os melhores provedores. Nessa lista encontram-se o GoogleDrive, o OneDrive e o Dropbox, provedores escolhidos para serem averiguados no presente trabalho.

Os doutrinadores, como Marcel Leonardi (2005, p. 27), estabelecem uma classificação aos provedores de serviços de Internet. Os cloud computing providers podem ser enquadrados como provedores de hospedagem, haja vista que oferecem espaço na rede para o armazenamento de arquivos, além de possibilitarem que terceiros acessem esses dados, desde que previamente estipulado. Ademais, esse serviço normalmente é ofertado de forma onerosa, podendo haver remuneração direta ou indireta por parte do consumidor - esta segunda ocorre quando o consumidor tem franqueado o acesso aos serviços em troca da permissão para que seus dados sejam disponibilizados a empresas terceiras, o que o torna alvo de posterior envio de publicidade.

Ocorre que com a advento da Lei No 12.965 de 2014, conhecida também como Marco Civil da Internet, os provedores receberam nova denominação, pois tal normativa trouxe em seu texto as 
expressões “provedor de conexão à internet” e “provedor de aplicações de internet” (BRASIL, 2016a).

O primeiro refere-se aos provedores de acesso ou de conexão à Internet, não havendo grandes dificuldades quanto a essa conclusão. Já o segundo "é um termo que descreve qualquer empresa, organização ou pessoa natural que, de forma profissional ou amadora, forneça um conjunto de funcionalidades que podem ser acessadas por meio de um terminal conectado à internet, não importando se os objetivos são econômicos” (CEROY, 2014). Disso se extrai que os provedores de hospedagem, e assim os cloud computing providers, nada mais são do que provedores de aplicações de Internet.

\subsection{TERMOS DE RESPONSABILIDADE DOS CLOUD COMPUTING PROVIDERS: ESTUDO COMPARADO}

O primeiro provedor a ser analisado nesse estudo é o GoogleDrive, cujo serviço é oferecido pela empresa Google, mundialmente conhecida. Em sua homepage na Internet, o GoogleDrive expõe algumas de suas funcionalidades, como a capacidade inicial para o armazenamento de arquivos, como fotos e vídeos, que é de 15 GB. Também enfatiza a possibilidade de acesso desses conteúdos em qualquer lugar e por diferentes meios, como smartphones, tablets ou computadores. E, por fim, explica que os arquivos e pastas podem ser compartilhados e editados com e por outras pessoas (GOOGLEDRIVE..., 2016).

O fato é que, ao ler os termos de serviço do Google, na parte que trata da responsabilidade pelos serviços ofertados, a empresa se posiciona claramente pela exclusão de sua responsabilidade:

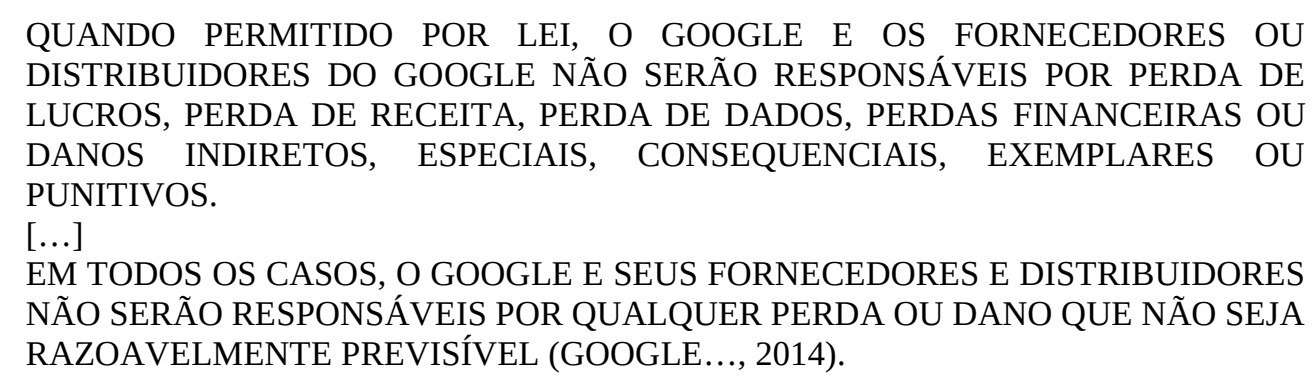
DISTRIBUIDORES DO GOOGLE NÃO SERÃO RESPONSÁVEIS POR PERDA DE LUCROS, PERDA DE RECEITA, PERDA DE DADOS, PERDAS FINANCEIRAS OU DANOS INDIRETOS, ESPECIAIS, CONSEQUENCIAIS, EXEMPLARES OU PUNITIVOS.

$[\ldots]$

EM TODOS OS CASOS, O GOOGLE E SEUS FORNECEDORES E DISTRIBUIDORES NÃO SERÃO RESPONSÁVEIS POR QUALQUER PERDA OU DANO QUE NÃO SEJA RAZOAVELMENTE PREVISÍVEL (GOOGLE..., 2014).

Com isso, e também pela intencional utilização de letras garrafais, percebe-se que o Google tenta, na medida do possível, isentar-se de responsabilidade, especialmente em razão de qualquer perda ou danos aos arquivos e materiais depositados no espaço por ele disponibilizado. Mas a empresa também destaca que tal isenção só ocorrerá quando permitida por lei, razão pela qual a legislação e a doutrina brasileira serão averiguadas nas subseções seguintes do presente trabalho. 
O OneDrive, segundo cloud computing provider cujos termos de uso são analisados, igualmente apresenta em sua página inicial algumas de suas funcionalidades. Tal provedor pertence à Microsoft, e por isso ele já vem pré-instalado no Windows 10 e alguns dos principais dispositivos do Office, como Word, Excel, PowerPoint e OneNote, podem ser inseridos e alterados na própria nuvem (ONEDRIVE..., 2016).

Quanto aos termos, o contrato de serviços da Microsoft dispõe de um tópico denominado “Limitação de Responsabilidade”, no qual consta que:

12. b. Você não poderá ser indenizado por (i) danos ou perdas consequenciais; (ii) perda de lucros reais ou antecipados (sejam eles diretos ou indiretos); (iii) perda de receita real ou antecipada (seja ela direta ou indireta); (iv) perda de contrato ou empresarial ou outras perdas ou danos decorrentes do uso que você faz dos Serviços em uma capacidade não pessoal; (v) perdas ou danos especiais, indiretos, incidentais ou punitivos e (vi) até a extensão permitida por lei, perdas ou danos diretos além da capacidade especificada na seção 12(a) acima ${ }^{3}$. Essas limitações e exclusões também se aplicam se esse recurso não compensá-lo totalmente por quaisquer perdas ou não cumprir sua finalidade essencial, ou se soubéssemos ou devêssemos saber sobre a possibilidade de tais danos. No limite máximo permitido pela lei, essas limitações e exclusões se aplicarão a todos ou quaisquer requerimentos judiciais ou extrajudiciais relacionados a estes Termos, aos Serviços ou ao software relacionado aos Serviços (CONTRATO..., 2015).

Diante disso, e assim como ocorre com o Google, a Microsoft também almeja eximir-se de responsabilidade. A diferença é que para isso a empresa acrescenta um termo buscando a concordância do consumidor de que caso o usuário possua algum mecanismo de recuperação de dados, será ele o encarregado pelo resgate das informações.

Quando a análise recai sobre o Dropbox constata-se que há um esforço da empresa para destacar o seu compromisso com o cliente, mantendo a confiança. De acordo com a descrição contida em seu próprio website, trata-se de "uma empresa de tecnologia que desenvolve produtos simples e poderosos para empresas e indivíduos”. Além disso, a empresa faz questão de evidenciar que valoriza a confiabilidade dos usuários em seus serviços, afirmando que todos os arquivos e dados estarão seguros em sua plataforma virtual. Para o provedor, “a privacidade de nossos usuários sempre foi nossa maior prioridade, e sempre será” (O DROPBOX..., 2016).

Com relação aos termos de serviço do Dropbox, percebe-se que há clara restrição de responsabilidade, conforme se constata:

\footnotetext{
${ }^{3}$ A seção 12(a) referida nesse trecho contempla que “12. a. Se você tiver alguma base para recuperar os danos (inclusive violação destes Termos), você concorda que seu recurso exclusivo será recuperar, da Microsoft ou de qualquer afiliada, revendedor, distribuidor, Aplicativos de Terceiros e Provedores de Serviços e fornecedores danos diretos até o valor equivalente ao valor pago por seus Serviços para o mês durante o qual ocorreu a violação (ou até USD\$10,00 se os Serviços forem gratuitos)” (CONTRATO..., 2015).
} 
ATÉ ONDE ADMITIDO POR LEI, COM EXCEÇÃO DE QUALQUER RESPONSABILIDADE RESULTANTE DE FRAUDE, DECLARAÇÕES FRAUDULENTAS OU NEGLIGÊNCIA GRAVE DO DROPBOX OU DE SUAS AFILIADAS, EM NENHUMA CIRCUNSTÂNCIA O DROPBOX, SUAS AFILIADAS, SEUS FORNECEDORES OU SEUS DISTRIBUIDORES SERÃO RESPONSÁVEIS PELO ENUMERADO ABAIXO:

(A) QUAISQUER DANOS INDIRETOS, ESPECIAIS, INCIDENTAIS, PUNITIVOS, EXEMPLARES OU CONSEQUENTES, OU

(B) POR QUALQUER PERDA DE USO, DADOS, NEGÓCIOS OU LUCROS, INDEPENDENTEMENTE DE TEORIA JURÍDICA (TERMOS..., 2016).

Mais uma vez verifica-se a tentativa do provedor de afastar sua responsabilidade diante do extravio de arquivos, dados, informações ou qualquer outro conteúdo que possa ser armazenado na nuvem. Além da clara tentativa de excluir a responsabilidade, existe algo em comum nos termos dos três provedores que se traduzem nas expressões “quando permitido por lei”, “no limite máximo permitido pela lei” e “até onde admitido por lei”. Isso significa que, muito embora o contrato de adesão firmado entre o provedor e os usuários/consumidores exista e seja efetivamente aplicável, os contratantes precisam observar também a legislação vigente para os contratos eletrônicos, conforme será analisado na sequência.

\subsection{CONTRATOS ELETRÔNICOS: QUESTÕES RELEVANTES}

Os contratos pactuados entre os respectivos provedores e os usuários nada mais são do que contratos de adesão. Para o autor Paulo Lôbo (2011, p. 129-130), esse é “o contrato que, ao ser concluído, adere a condições gerais predispostas ou utilizadas por uma das partes, que passam a produzir efeitos independentemente de aceitação da outra. Ou simplesmente: o contrato que adere a condições gerais”. Tal contrato se materializa, por conseguinte, quando em seu cerne já se encontram previamente estipuladas as cláusulas gerais, ficando a critério da outra parte aceitá-las ou não.

A doutrina especializada também denomina esta espécie de contrato, quando celebrados via Internet, como “contratos por clique” ou “click-through agréments”, justamente em razão de que eles se perfectibilizam quando os contratantes clicam na opção “aceitar” disponibilizada pelo contratado no ciberespaço (LAWAND, 2003, p. 103). Outra denominação encontrada é “contratos clickwrap”, sendo que para Finkelstein (2011, p. 207) “sua principal função é demonstrar que o usuário conhece as regras de uso do site, bem como as isenções de responsabilidade do fornecedor (disclaimers)”.

Todos os contratos, não apenas os de adesão, ofertados pela Internet com a finalidade de comercializar um bem ou um serviço, são denominados “contratos eletrônicos” (LÔBO, 2011, p. 33). Esses nada diferem dos demais, a não ser quanto à forma e o meio utilizado para a declaração de vontades. Alguns autores pontuam desvantagens na celebração desses contratos, a exemplo de: a) 
existirem cláusulas abusivas, em razão da falta de negociação; b) serem a maioria dos contratos eletrônicos, contratos de adesão; c) estar a privacidade dos usuários ameaçada, em função da falta de segurança no ciberespaço; d) possibilitarem a suscitação de dúvidas quanto às assinaturas digitais e às autoridades certificadoras (FINKELSTEIN, 2011, p. 177).

Muitos desses contratos são, também, contratos de consumo, e por isso devem obedecer às regras de Direito do Consumidor expressas na Lei No 8.078 de 1990. Essa legislação oferece, em seu artigo 54, a definição para contrato de adesão, assim entendido como “aquele cujas cláusulas tenham sido aprovadas pela autoridade competente ou estabelecidas unilateralmente pelo fornecedor de produtos ou serviços, sem que o consumidor possa discutir ou modificar substancialmente seu conteúdo” (BRASIL, 2016b).

Assim como ocorre com outros serviços ofertados por meio da Internet, como o Facebook, que também é um provedor de hospedagem ou de aplicações de Internet, muitos dos contratos de adesão firmados na área da computação em nuvem são apenas aparentemente gratuitos, já que costumam ser remunerados de forma indireta, não deixando, portanto, de configurar relação de consumo (VELTE; VELTE; ELSENPETER, 2012).

Nesse sentido também entendem Castro, Queiroz e Jardim (2010), para quem contratos firmados entre os usuários e os provedores de computação em nuvem nada mais são que contratos de adesão eletrônicos, em razão da sua celebração e do seu baixo custo. Ademais, os autores também identificam a existência de uma relação de consumo entre usuário e provedor no Brasil, e criticam a inexistência de uma legislação que regulamente tal relação de forma específica.

Uma das questões mais controversas no direito brasileiro, envolvendo contratos eletrônicos, diz respeito às incertezas quanto à fixação do foro e da lei aplicável diante de conflito, já que uma das partes - qual seja, a empresa contratada - encontra-se sediada no estrangeiro, e a outra, a parte contratante, é brasileira ou domiciliada no Brasil. Esse aspecto mostra-se relevante pois, no caso em estudo, duas das empresas em análise possuem filiais no País, e uma não. O Google, embora sediado nos Estados Unidos, possui filiais em Belo Horizonte e São Paulo (GOOGLE..., 2014). Já a Microsoft, responsável pelo OneDrive, conta com escritórios em Belo Horizonte, Brasília, Curitiba, Porto Alegre, Rio de Janeiro e São Paulo (CONTRATO..., 2015). Somente o Dropbox não tem nenhuma filial ou escritório no Brasil, estando sediado na América do Norte (O DROPBOX..., 2016).

Como inexiste uma norma que solucione expressamente essa questão, coube à doutrina posicionar-se sobre o assunto, não havendo, contudo, uma resposta unânime por parte dos estudiosos. Autores como Marcos Relvas (2005, p. 84) entendem como "local da formação do contrato aquele onde as partes se encontram no momento de sua formação, quando entre presentes, ou de onde 
emanou a proposta quando entre ausentes”. Essa conclusão é extraída do artigo 9º e parágrafos, do Decreto-Lei N 4.657 de 1942, ou Lei de Introdução às Normas do Direito Brasileiro - LINDB (BRASIL, 2016c).

Essa regra é aplicável aos contratos eletrônicos simplesmente pelo fato de que não há como a parte contratada conhecer todas as legislações existentes em todos os países do mundo e, portanto, não convém aplicar a lei do lugar onde a parte contratante se encontra (FINKELSTEIN, 2011, p. 219). Só que essa questão é muito delicada em termos de Direito do Consumidor, pois, como afirma Paulo Lôbo (2011, p. 36),

O ambiente virtual não considera fronteiras nacionais, o que aguça a necessidade de se saber qual o direito aplicável aos contratos eletrônicos internacionais. A legislação brasileira (CC, art. 435; LICC, art. $9^{\circ}, \S 2^{\circ}$ ) considera que o lugar do contrato é o da oferta ou proposta. Essa regra, todavia, contraria o princípio constitucional de defesa do consumidor, pois agrava suas condições de acesso à justiça; assim, nos contratos de consumo, a regra prevalecente é a de seu melhor benefício, inclusive para os contratos eletrônicos internacionais, pelo fato de a proteção do consumidor ser dever de todos os Estados membros da ONU, por força de Resolução específica, editada em 9 de abril de 1985.

Aos termos dessa Resolução se soma o compromisso brasileiro, firmado em sede constitucional, de o Estado defender o consumidor. Não é sem motivo, portanto, o disposto no Enunciado 173 do Conselho da Justiça Federal, aprovado na Terceira Jornada de Direito Civil, segundo o qual “a formação dos contratos realizados entre pessoas ausentes, por meio eletrônico, completa-se com a recepção da aceitação pelo proponente” (AGUIAR JÚNIOR, 2012, p. 38).

Percebe-se, com isso, a existência de um conflito de normas e de posições entre os autores. Ocorre que, deve-se ter em mente que o consumidor do serviço de computação em nuvem é a parte mais vulnerável dessa relação, seja pela questão técnica que a contratação em nuvem envolve, seja em virtude de realizar contrato de adesão com empresa estrangeira por meio da rede mundial de computadores, o que justifica a fixação do foro e da lei aplicável em benefício dos usuários/consumidores. Ademais, as próprias cláusulas contratuais, expostas anteriormente, foram estabelecidas com ressalvas no sentido de respeitar a legislação, o que por certo deve remeter à legislação brasileira.

Realizadas essas principais considerações acerca dos contratos eletrônicos, com a finalidade de compreender como ocorre sua formação, especialmente a formação dos contratos de computação em nuvem, na sequência será enfrentado o tema da responsabilidade civil ante a perda ou extravio de conteúdo desses ambientes on-line. 


\subsection{RESPONSABILIDADE CIVIL: ENFRENTAMENTO DO TEMA}

Com base em todo o exposto até o presente momento, nesta subseção será enfrentado o tema da responsabilidade civil diante da perda ou extravio de arquivos depositados nos cloud computing providers GoogleDrive, OneDrive e Dropbox. Para tanto, será estudada a responsabilidade civil advinda do Código Civil, do Código de Defesa do Consumidor e do Marco Civil da Internet.

O Código Civil brasileiro prevê, como regra geral, a responsabilidade subjetiva, e como exceção, a responsabilidade objetiva. A primeira, contemplada pelo caput do artigo 927 da lei, é aquela advinda de um ato ilícito. Cavalieri Filho (2012, p. 19), ao elencar os pressupostos da responsabilidade subjetiva, afirma que "há primeiramente um elemento formal, que é a violação de um dever jurídico mediante conduta voluntária; um elemento subjetivo, que pode ser o dolo ou a culpa; e, ainda, um elemento causal-material, que é o dano e a respectiva relação de causalidade”. Presentes todos esses requisitos, quais sejam, conduta culposa, nexo causal e dano, nasce a obrigação de indenizar.

A responsabilidade subjetiva adota, portanto, a teoria da culpa, considerando que a ação é humana. Significa dizer que “o homem não deve responder senão pelas ações verdadeiras e perfeitamente humanas e pelas consequências desta”. Contudo, se esta espécie de responsabilidade se mostrava adequada para as situações menos complexas, sua insuficiência se revelou evidente à medida que a sociedade passou a conviver com novas tecnologias, incorporando-as ao seu cotidiano, o que fazia com que a vítima em muitos casos restasse sem a devida reparação.

Para corrigir esse problema e dar suporte à vítima desenvolveu-se a responsabilidade objetiva, ou responsabilidade sem culpa, pautada na teoria do risco, pois, para Cavalieri Filho (2012, p. 152), “aquele que exerce uma atividade perigosa deve-lhe assumir os riscos e reparar o dano dela decorrente".

Na responsabilidade objetiva, o criador do risco, mesmo exercendo uma atividade lícita, será responsabilizado se o risco vier a se concretizar; não por haver conduta dolosa ou culposa, mas sim por haver fato danoso. Nesse sentido, "quem causa um dano não responde por ele como culpado de sua produção, mas como autor do dano” (GARCEZ NETO, 2000, p. 96). Para uma melhor compreensão desse fenômeno, Garcez Neto (2000, p. 96-97) dispõe que:

Basta que uma pessoa ou os seus bens tenham sofrido dano por ação ou omissão de outra pessoa para que esta deva repará-lo, qualquer que tenha sido a sua conduta e ainda que a ação ou omissão não possa ser imputada a dolo ou culpa do agente, salvo, naturalmente, se ficar provado que o dano resultou de caso fortuito ou de força maior, ou de fato exclusivo da vítima ou de um terceiro, casos em que cessaria completamente a sua responsabilidade. 
Tanto a responsabilidade subjetiva quanto a objetiva são modalidades extracontratuais. Existe, contudo, a responsabilidade contratual, que "é o dever de reparar o dano decorrente do descumprimento de uma obrigação prevista no contrato”, mas tanto essa quanto aquelas decorrem da violação de dever jurídico preexistente (CAVALIERI FILHO, 2012, p. 305). A responsabilidade contratual, por seu turno, exige a realização de contrato válido, inexecução do negócio jurídico, dano e nexo causal (CAVALIERI FILHO, 2012, p. 308).

Essas obrigações derivadas do negócio jurídico são regidas pelo princípio da boa-fé objetiva, previsto no artigo 422 do Código Civil brasileiro e um dos sustentáculos do Código de Defesa do Consumidor. De acordo com Martins-Costa (2000, p. 411), a boa-fé objetiva está fundada na lealdade e na honestidade e se traduz numa "norma de comportamento leal".

Desse princípio decorrem deveres de conduta para ambas as partes envolvidas no negócio jurídico, tais como o dever de lealdade, respeito e colaboração. Tais deveres, enumerados por Couto e Silva (2006, p. 34) levam o autor a destacar que

Nos negócios bilaterais, o interesse conferido a cada participante da relação jurídica (mea res agitur), encontra sua fronteira nos interesses do outro figurante, dignos de serem protegidos. O princípio da boa-fé opera, aqui, significativamente, como mandamento de consideração.

A boa-fé objetiva determina que a conduta ética das partes seja observada ao longo de todas as etapas da contratação, do contato social à etapa pós-contratual. Esse alcance da boa-fé objetiva, desde a etapa do contato social, não consiste em novidade na doutrina brasileira, sendo fonte obrigacional citada desde a década de setenta por Couto e Silva (2006, p. 76), para quem as atividades pré-contratuais “constituem-se em atos concretos, dirigidos a pessoas também concretamente determinadas, revelando interesses, à sua vez, concretos”. Logo, esse princípio acompanha toda a vida da relação obrigacional, vista como totalidade concreta e na perspectiva de um processo, expressão utilizada pelo autor para “sublinhar o ser dinâmico da obrigação, as várias fases que surgem no desenvolvimento da relação obrigacional e que entre si se ligam com interdependência” (COUTO E SILVA, 2006, p. 20).

Deve vigorar, portanto, a confiança entre as partes, que depositam a legítima expectativa de que o outro polo da relação jurídica contratual não irá, de maneira injustificada, desrespeitar os deveres derivados do ajuste de vontades. À luz dessas definições pode-se afirmar que esse princípio serve de importante balizador ao presente estudo, visto que o titular dos dados possui legítima expectativa de que o provedor irá custodiar e zelar pela segurança das suas informações, depositadas na nuvem. 
Assim, as obrigações entre as partes devem ficar claras já no momento da formação do contrato, pois seus deveres não decorrem exclusivamente das cláusulas contratuais, procedendo também da boa-fé objetiva, cujos deveres instrumentais de informação, de cuidado, de colaboração, de segredo e de guarda não podem ser desconsiderados.

Na mesma linha argumentativa, Ilha (2004, p. 79) sustenta que já nas tratativas os deveres de colaboração, cooperação e confiança devem regular as atitudes de todos os envolvidos. A autora cita, ainda, o sigilo como dever que decorre da informação, e, para ela, "aquele que, durante as negociações preliminares, obtiver conhecimento de questões referentes à contraparte, não poderá divulgá-las a pessoas alheias à relação” (ILHA, 2004, p. 80).

Percebe-se, assim, que o sigilo também pode ser relacionado à observância da confiança entre as partes, corroborando os ensinamentos de Claudia Lima Marques (1998, p. 37), para quem “o contrato não envolve só a obrigação de prestar, mas envolve também uma obrigação de conduta”.

Ademais, modernamente a ideia de boa-fé objetiva também pode ser estendida para as obrigações extracontratuais, já que, independentemente de culpa do ofensor, deve-se pensar no atendimento dos interesses da vítima lesada, mesmo que o ataque aos seus direitos tenha decorrido de atividade de risco da outra parte. Com efeito, a divisão da responsabilidade civil em sendas apartadas não seduz a todos os autores, havendo vozes que sustentam a unificação da responsabilidade a partir de uma nova teoria:

Proclama essa teoria que a responsabilidade é sempre e necessariamente delitual e que a expressão responsabilidade contratual não passa de uma forma viciosa e errônea de linguagem, posto que os mesmos princípios que regulam a responsabilidade extracontratual regulam também a responsabilidade contratual (CAVALIERI FILHO, 2012, p. 306).

Assim, a responsabilidade civil que rege o Código Civil é em regra a subjetiva, e a exceção será a responsabilidade objetiva, diferentemente do que ocorre no Código de Defesa do Consumidor, que prevê a responsabilidade objetiva aparece como regra e a subjetiva como exceção. Sendo assim, a indenização derivada da relação de consumo, salvo disposição em contrário, sujeita-se ao regime da responsabilidade objetiva, a qual independe de dolo ou culpa do agente; ou seja, é suficiente a existência do dano efetivo ao ofendido e a comprovação do nexo causal.

Esse fato pode ser constatado da leitura dos artigos 12 e 14 da Lei 8.078/90, que assim o determinam em homenagem aos princípios da vulnerabilidade e hipossuficiência do consumidor. Pode-se entender que, no momento em que for constatado o fato que gerou o dano, na relação de consumo, não há a necessidade de o consumidor apresentar prova de culpa, cabendo ao responsável a sua reparação, constatação que é corroborada pelas lições de Claudia Lima Marques (2006), para 
quem a responsabilidade do fornecedor, em seus aspectos contratuais e extracontratuais, presente nas normas do CDC, é objetiva e deriva do produto ou serviço prestado, nos quais se constata defeito ou vício.

Sobre vulnerabilidade, de acordo com os autores Claudia Lima Marques e Bruno Miragem (2012, p. 117), pode ser entendida como “um estado da pessoa, um estado inerente de risco, ou um sinal de confrontação excessiva de interesses identificado no mercado, é uma situação permanente ou provisória, individual ou coletiva, que fragiliza, enfraquece o sujeito de direitos, desequilibrando a relação".

Na concepção de Claudia Lima Marques (2006, p. 144), o princípio da vulnerabilidade está diretamente relacionado com o princípio da igualdade. Aquele que é vulnerável necessariamente se encontra em situação desigual, o que é marcado pela confrontação excessiva de interesses identificada no mercado. Tal condição se intensifica em face das assimetrias entre o usuário e os provedores que hospedam conteúdos na nuvem, tanto devido ao poderio econômico dos gigantes da Internet, quanto em razão da marcante tecnicidade que envolve o conteúdo.

Tal quadro de assimetria gera, portanto, uma hipervulnerabilidade, delineada por termos como "vulnerabilidade potencializada" - trata-se de um conceito implícito no ordenamento jurídico brasileiro, que se recolhe de princípios constitucionais.

A partir dos dispositivos mencionados anteriormente, compreende-se que a obrigação de o fornecedor reparar os danos sofridos pelo consumidor surge tanto do vínculo contratual quanto em decorrência do nexo causal entre a conduta do agente e o dano daí resultante. Nesse caso, e por se tratar de relação de consumo, a responsabilidade daí resultante é objetiva, baseada no risco. Tal posição se mostra em sintonia com as bases principiológicas que servem de pilares ao CDC, que visa a evitar práticas abusivas realizadas por fabricantes, fornecedores, prestadores de serviços ou comerciantes.

Nesse sentido, Aguiar (2007, p. 29) destaca que é

curioso observar, inclusive, que a objetivação da responsabilidade no campo das relações de consumo não foi tomada como apenas mais um elemento da nova realidade jurídica que se erigia então - tornou-se verdadeiramente a viga mestra da revolução cultural operada neste campo, onde o consumidor descobriu-se "escudado" contra o poderio econômico e jurídico dos fornecedores.

Ao tratar do tema, Benjamin (2012, p. 146-147) aborda a "responsabilidade pelos acidentes de consumo”, expressão que utiliza para evidenciar o “destaque ao elemento humano consequencial”, pois para ele “o dado fundamental não é a origem do fato (do produto ou serviço), mas sim a 
localização humana de seu resultado (o acidente de consumo)”. Aprofundando o tema, Benjamin (2012, p. 147) considera que:

\begin{abstract}
"Fato do produto" ou "fato do serviço" quer significar dano causado por um produto ou por um serviço, ou seja, dano provocado (fato) por um produto ou um serviço. [...] O novo regime desta matéria quer dizer exatamente isto: o Código Civil, em matéria de danos causados por produtos ou serviços de consumo, é afastado, de maneira absoluta, pelo regime especial do Código de Defesa do Consumidor. Só excepcionalmente aplica-se o Código Civil, ainda assim quando não contrarie o sistema e a principiologia (art. $4^{\circ}$ ) do Código de Defesa do Consumidor.
\end{abstract}

Corroborando com esse pensamento, Melo (2010) afirma que “a Lei n. 8.078/90 será aplicada sempre que houver relação de consumo não importando a área do Direito em que ela ocorra, sempre que os elementos da relação de consumo estiverem presentes a legislação correta a ser utilizada é o Código de Defesa do Consumidor”. Portanto, nos casos de relações consumeristas, como os contratos de adesão em análise, será aplicada a Lei 8.078/90.

Flumignan (2015) considera que nas relações do usuário com os provedores de Internet deve existir a incidência do CDC, devendo o internauta ser considerado consumidor, uma vez que o artigo $2^{\circ}$, caput, do CDC define consumidor como "toda pessoa física ou jurídica que adquire ou utiliza produto ou serviço como destinatário final”. O autor destaca, também, que no artigo $3^{\circ}$, $\S 2^{\circ}$, está estipulado que "serviço é qualquer atividade fornecida ao mercado de consumo, mediante remuneração, inclusive as de natureza bancária, financeira, de crédito e securitária, salvo as decorrentes de caráter trabalhista”.

Logo, se o provedor não cumprir com seus deveres e prestar serviço defeituoso, informações insuficientes ou inadequadas, falhar no dever de cuidado, resultando no extravio de arquivos, incidirá no artigo 14 da referida lei, a qual implica a imputação da responsabilidade objetiva pelos danos causados. Contudo, poderia o provedor isentar-se de tal responsabilidade, se provasse que o defeito inexiste ou que a culpa foi exclusivamente do consumidor ou de terceiro, segundo o que consta no artigo $14, \S 3^{\circ}$, do CDC.

Com relação à responsabilidade civil dos provedores de Internet, algumas mudanças ocorreram com o advento da Lei $\mathrm{N}^{\mathrm{o}} 12.965 / 14$. Entretanto, o artigo $7^{\circ}$, inciso XIII, da referida norma, reafirma a aplicação das regras do CDC nas relações estabelecidas via Internet, desde que reconhecida uma relação de consumo.

O Marco Civil, para Tarcísio Teixeira (2015, p. 343), “trata-se de uma lei principiológica que estabelece parâmetros gerais acerca de princípios, garantias, direitos e deveres para o uso da Internet no Brasil”. Na mesma senda, o autor De Lucca (2015, p. 45) afirma que “tudo o que existe no mundo jurídico - sejam princípios, sejam simplesmente regras - constituem, em última análise, 
normas”, e, dentre os princípios do artigo $3^{\circ}$, encontram-se o da proteção da privacidade, no inciso II, e o da proteção dos dados pessoais, na forma da lei, no inciso III (BRASIL, 2016a).

Portanto, ainda que inexista no Brasil uma legislação específica que regulamente a proteção de dados pessoais no ambiente virtual, alguns autores compreendem que o não cumprimento de um princípio, aqui entendido como norma, é a forma mais grave de inconstitucionalidade ou ilegalidade, o que não afastaria as consequências jurídicas advindas dessa violação (DE LUCCA, 2015, p. 50).

Assim sendo, os provedores de computação em nuvem devem priorizar a privacidade dos dados e informações disponibilizadas nesses ambientes on-line, mesmo ante essa lacuna, visto que os princípios, entre eles o da boa-fé objetiva, desempenham tanto a função bloqueadora, para impedir comportamentos contraditórios e que frustrem as legítimas expectativas depositadas, quanto função integradora, suprindo eventuais lacunas legais e contratuais.

Sob outra perspectiva, autores como Vinícius Borges Fortes (2016, p. 101-108), compreendem que a proteção de dados pessoais no País e no mundo se fundamenta para além de bases principiológicas, pois também se trata de um direito fundamental e, mais do que isso, de um direito humano, assim como o direito à privacidade. O autor emprega o termo "privacidade" como um conceito amplo, englobando, portanto, a proteção da vida privada e da intimidade, assim como a inviolabilidade dos dados pessoais. Ademais, também defende a incorporação do termo “direitos de privacidade na internet” na legislação, como acréscimo necessário ante a nova realidade tecnológica, em que os internautas estão cada vez mais vulneráveis.

Nas palavras de Fortes (2016, p. 220):

A recepção expressa dos direitos de privacidade na internet, a partir dos direitos-base
conjuntamente considerados pelas normas juŕdicas que tratam, e ainda tratarão, de temas
afins no Brasil, permite a recomposição do núcleo do direito fundamental à privacidade que,
de acordo com as teorias apresentadas nesta obra, integram tão somente a proteção da vida
privada, da honra, da intimidade, da imagem e dos dados pessoais. Em outras palavras, o
direito fundamental à privacidade deve também integrar à sua estrutura nuclear os direitos de
privacidade na internet, quais sejam o direito de navegar na internet com privacidade; o
direito de monitorar quem monitora; o direito de deletar os dados pessoais; o direito à
proteção da identidade online.

Tudo isso, somado à notável exposição dos cidadãos no ambiente on-line, onde seus dados muitas vezes são coletados, armazenados e utilizados para diversas finalidades, faz com que os juristas assumam a missão de encontrar formas de proteger a privacidade e os dados pessoais dos usuários e consumidores na Internet. Tal missão não será algo simples e, em grande medida, dependerá da colaboração dos provedores de Internet para a sua efetivação. Portanto, a relação de colaboração e de transparência entre consumidores e provedores é indispensável para o bom 
funcionamento da rede, em especial quando da ocorrência de infortúnios, como o extravio de arquivos.

Para Laura Schertel Mendes (2015, p. 28), “ao se examinar o tratamento de dados pessoais realizado no âmbito da relação de consumo, é fundamental se considerar a vulnerabilidade do consumidor nesse processo”. De acordo com a autora, isso se justifica devido ao fato de que os dados pessoais, assim como as demais informações extraídas a partir deles, constituem-se em uma representação virtual da pessoa perante a sociedade, ampliando ou reduzindo as suas oportunidades no mercado, conforme a sua utilização. O risco ao consumidor ocorre, principalmente, quando o tratamento dos dados é realizado de forma descuidada, equivocada ou discriminatória, acarretando o posterior cerceamento de oportunidades, o que afeta expressivamente o seu acesso a bens e serviços e as suas oportunidades sociais.

A matéria, apesar de importante, não foi diretamente abordada pelo Marco Civil da Internet, que se limitou a dispor sobre os deveres dos provedores de aplicação a partir do princípio da inimputabilidade da rede. Conforme consta no artigo 19 da referida lei, há previsão de responsabilizar o provedor de aplicações de Internet por prejuízos advindos de conteúdo gerado por terceiros, quando o fornecedor deixar de cumprir, em tempo hábil, ordem judicial específica determinando a indisponibilização do conteúdo violador. Trata-se de um retrocesso se considerada a imperiosa defesa do consumidor, sobretudo porque a jurisprudência anterior ao Marco Civil da Internet tutelava o consumidor de forma mais efetiva.

Outro dispositivo que se aplica aos provedores de aplicação é o artigo 21, segundo o qual se impõe o dever de o provedor de conteúdo retirar, mediante simples notificação extrajudicial, materiais contendo cenas de nudez ou de atos sexuais privados, publicados sem autorização/consentimento, o que deve ser feito sob pena de ser subsidiariamente responsável. Flumignan (2015) considera que "para a responsabilização e identificação de eventuais danos causados por terceiros na internet é essencial que os provedores preservem e forneçam os registros eletrônicos utilizados na prática ilícita”. Sobre esse aspecto, a Lei $\mathrm{N}^{\circ} 12.965 / 14$ estabelece, em seu artigo 15, que os provedores de aplicações de Internet devem manter os registros de acesso às aplicações, em ambiente controlado, pelo prazo de apenas seis meses. Isso auxiliará os provedores de computação em nuvem a identificarem e corrigirem as falhas em seus sistemas, evitando, assim, futuras perdas ou extravios de arquivos pertencentes aos seus consumidores.

Pode-se afirmar que a Lei $N^{\circ}$ 12.965/14 é um avanço nas relações jurídicas estabelecidas pelo uso da Internet. Contudo, como visto anteriormente, ela apresenta lacunas quanto a eventuais danos derivados do armazenamento em nuvem, o que evidencia que tanto o Código Civil, quanto o 
Código de Defesa do Consumidor e, também, o Marco Civil da Internet abordam a questão da responsabilidade civil, mas diferentemente.

As autoras Silva e Finkelstein (2014, p. 510) criticam a morosidade do Poder Legislativo, brasileiro e de outros países, na regulação da computação em nuvem. Para elas, "a ausência de uma legislação específica dificulta a disseminação do serviço e torna ‘insegura’ a utilização da nuvem”. De fato, houvesse uma legislação em que a privacidade e a proteção de dados fossem contempladas e regulamentadas, principalmente em situações de extravio de arquivos, haveria mais segurança para o enfrentamento desses novos temas.

Ainda que alguns doutrinadores, como Claudia Lima Marques, sugiram o diálogo das fontes para casos difíceis, deve-se ter em mente que o usuário/consumidor do serviço de computação em nuvem é sempre a parte mais vulnerável da relação e, portanto, seus direitos devem ser respeitados, garantidos e, quando violados, ressarcidos.

Assim, perante a ausência de legislação específica que regulamente a responsabilidade civil dos cloud computing providers derivada da perda de arquivos, entende-se que o tema deve ser regido pelo princípio da boa-fé objetiva, um dos pilares sobre o qual se construiu o Código de Defesa do Consumidor. Ademais, a aplicação dessa norma apresenta-se como a mais adequada para proteger o usuário/consumidor, a parte mais vulnerável dessa relação contratual que se notabiliza pela complexidade e risco, típicas da sociedade em rede.

\section{CONCLUSÃO}

Levando-se em consideração todo o exposto no presente trabalho, é possível chegar a algumas conclusões. Primeiro, constatou-se que de fato a computação em nuvem é um método ofertado por uma empresa, que pode ser utilizado tanto por pessoas físicas como jurídicas, o qual tem o objetivo de fornecer serviços, como armazenamento, backup de conteúdo, processamento, entre outros. As pessoas, assim, podem ter acesso aos seus dados, de forma teoricamente segura, de qualquer lugar e a qualquer tempo, o que se coaduna com os ideais da sociedade em rede, marcada por espaços de fluxos e tempos atemporais.

Foi possível constatar, com o advento da Lei N ${ }^{\circ} 12.965$ de 2014, que os provedores receberam nova denominação: os de “conexão à internet” e os “provedores de aplicações de internet”, o que justificou a denominação adotada neste estudo, que identificou os cloud computing providers como provedores de aplicações de Internet. 
A análise dos termos de responsabilidade dos cloud computing providers GoogleDrive, OneDrive e Dropbox, por sua vez, evidenciou que nos três casos há clara tentativa de o provedor afastar sua responsabilidade diante do extravio de arquivos, dados, informações ou qualquer outra informação ou conteúdo que possam ser armazenados na nuvem.

Tal comportamento não se coaduna com os princípios protetivos do consumidor, especialmente o da boa-fé objetiva, pois ferem a confiança do usuário, que espera que o provedor que disponibiliza o espaço e lucra com o serviço ofereça a contrapartida necessária a qualquer negociação, zelando pela segurança do armazenamento. Essa preocupação, no entanto, não se verifica nas condutas das empresas, cujos termos de uso, bastante similares entre si, fazem referências evasivas à legislação, valendo-se de expressões como “quando permitido por lei”, “no limite máximo permitido pela lei” e “até onde admitido por lei”.

Essas ressalvas revelam a clara tentativa de se furtar de suas responsabilidades, olvidandose que o contrato envolve bem mais do que o cumprimento das obrigações principais. Com efeito, ambas as partes devem observar os deveres de colaboração e a ética e não frustrar as legítimas expectativas uma da outra, pois por certo quem hospeda conteúdos na nuvem tem a legítima expectativa de segurança que não pode ser afastada por cláusulas contratuais em contrato de adesão, disposições que afrontam a legislação consumerista.

O fato de o serviço prestado pelo provedor de serviço de Internet ser gratuito não desvirtua a relação de consumo, pois o termo "mediante remuneração", contido no artigo $3^{\circ}, \S 2^{\circ}$, do CDC, deve ser interpretado de forma ampla, de modo a incluir o ganho indireto do fornecedor, obtido por meio da publicidade e do fornecimento de dados. Tal interpretação infirma qualquer tese no sentido de afastar a incidência do Código de Defesa do Consumidor. Ademais, outra não poderia ser a conclusão após o diálogo de fontes e a análise combinada da responsabilidade civil no âmbito do Código Civil, do Código de Defesa do Consumidor e do Marco Civil da Internet, o que foi feito especialmente com foco na perda ou extravio de arquivos depositados nos cloud computing providers, objetos de estudo do presente trabalho.

Conclui-se que ainda que o Brasil não conte com dispositivos legais ou legislação específica para regular a atuação dos provedores que disponibilizam espaço para armazenamento na nuvem, as indagações e conflitos postos a partir dessas novas práticas contratuais podem ser solucionados de maneira satisfatória a partir do princípio da boa-fé objetiva, presente tanto na legislação civilista quanto no Código de Defesa do Consumidor, aplicável com maior propriedade nos contratos em tela. Esse diálogo das fontes à luz do princípio da boa-fé objetiva se mostra adequado e, por ora, a principal estratégia na defesa dos consumidores em face das empresas que hospedam conteúdos na nuvem. 


\section{REFERÊNCIAS}

AGUIAR JÚNIOR, Ruy Rosado de. Jornadas de direito civil I, III, IV e V: enunciados aprovados. Brasília: Conselho da Justiça Federal, Centro de Estudos Judiciários, 2012. Disponível em: <https://goo.gl/sU2wyZ>. Acesso em: 25 fev. 2017.

AGUIAR, Roger Silva. Responsabilidade civil objetiva: do risco à solidariedade. São Paulo: Atlas, 2007.

AQUINO, Hilda. Brasil e México reúnem o maior número adeptos da computação em nuvem, aponta pesquisa global da GfK. GfK. 29 jul. 2015. Disponível em: <https://goo.gl/N2nn2x>. Acesso em: 7 mar. 2016.

BENJAMIN, Antonio Herman V. Fato do produto e do serviço. In: BENJAMIN, Antonio Herman V.; MARQUES, Claudia Lima; BESSA, Leonardo Roscoe (Coord.). Manual de Direito do Consumidor. 4. ed. São Paulo: Editora Revista dos Tribunais, 2012.

BRASIL. Decreto-Lei 4.657, de 04 de Setembro de 1942. Lei de Introdução às Normas do Direito Brasileiro (LINDB). Vade Mecum OAB e concursos. 8. ed. São Paulo: Saraiva, 2016c.

BRASIL. Lei 12.965, de 23 de Abril de 2014. Marco Civil da Internet. Vade Mecum OAB e concursos. 8. ed. São Paulo: Saraiva, 2016a.

BRASIL. Lei 8.078, de 11 de Setembro de 1990. Código de Defesa do Consumidor. Vade Mecum OAB e concursos. 8. ed. São Paulo: Saraiva, 2016 b.

CASTELLS, Manuel. A Galáxia da Internet: reflexões sobre a Internet, os negócios e a sociedade. Rio de Janeiro: Jorge Zahar Editor, 2001.

CASTELLS, Manuel. O poder da Comunicação. Lisboa: Fundação Caloust Gulbenkian, 2013.

CASTRO, Clarice Marinho Martins; QUEIROZ, Ruy José Guerra Barretto de; JARDIM, Natália Porto. Computação em nuvem e seus desafios nos contratos eletrônicos. Revista Jurídica INPACTUM, jun. 2010. Disponível em: <https://goo.gl/4CyRMZ>. Acesso em: 17 nov. 2017.

CAVALIERI FILHO, Sergio. Programa de responsabilidade civil. 10. ed. São Paulo: Atlas, 2012.

CEROY, Frederico Meinberg. Os conceitos de provedores do Marco Civil da Internet. Set. 2014. JusNavigandi. Disponível em: <https://goo.gl/tWaKzD>. Acesso em: 9 mar. 2016.

CLOUD computing (computação nas nuvens). Globo Tecnologias. Dez. 2015. Disponível em: <https://goo.gl/fv5m7c>. Acesso em: 4 abr. 2016.

CONTRATO de serviços da Microsoft. Microsoft. 01 ago. 2015. Disponível em: $<$ https://goo.gl/CsFrtk>. Acesso em: 7 mar. 2016.

COUTO E SILVA, Clóvis V. A obrigação como processo. Reimpressão. Rio de Janeiro: FGV, 2006. 
DE LUCCA, Newton. Marco civil da Internet - uma visão panorâmica dos principais aspectos relativos às suas disposições preliminares. In: DE LUCCA, Newton; SIMÃO FILHO, Adalberto; LIMA, Cíntia Rosa Pereira de (coords.). Direito \& Internet III - Tomo I: Marco Civil da Internet (Lei n 12.965/2014). São Paulo: Quartier Latin, 2015.

FINKELSTEIN, Maria Eugênia Reis. Direito do comércio eletrônico. 2. ed. Rio de Janeiro: Elsevier, 2011.

FLUMIGNAN, Wévertton Gabriel Gomes. A responsabilidade civil dos provedores de aplicações no Marco Civil da Internet. Ago. 2015. Disponível em: <https://goo.gl/ojnxRD>. Acesso em: 22 ago. 2016.

FORTES, Vinicius Borges. Os direitos de privacidade e a proteção de dados pessoais na Internet. Rio de Janeiro: Lumen Juris, 2016.

GARCEZ NETO, Martinho. Responsabilidade civil no direito comparado. Rio de Janeiro: Renovar, 2000.

GOOGLE Privacidade e Termos. Termos de serviço do Google. 14 abr. 2014. Disponível em: <https://goo.gl/XR1m1P>. Acesso em: 7 mar. 2016.

GOOGLEDRIVE, todos os seus arquivos, sempre que você precisar. Disponível em: $<$ https://goo.gl/ajFXpr>. Acesso em: 9 mar. 2016.

GREENWALD, Glenn. Sem lugar para se esconder: Edward Snowden, a NSA e a espionagem do governo americano. Tradução Fernanda Abreu. Rio de Janeiro: Sextante, 2014.

HIGA, Paulo. Comparativo: os melhores serviços de armazenamento de arquivos na nuvem. Tecnoblog. 02 fev. 2016. Disponível em: <https://goo.gl/IsW1mG>. Acesso em: 7 mar. 2016.

ILHA, D. D. Boa-fé objetiva na formação dos contratos de trabalho. Santa Maria: UNIFRA, 2004. Trabalho Final de Graduação (Curso de Direito), Centro Universitário Franciscano, Santa Maria, 2004.

LAWAND, Jorge José. Teoria geral dos contratos eletrônicos. São Paulo: Editora Juarez de Oliveira, 2003.

LEONARDI, Marcel. Responsabilidade civil dos provedores de serviços de Internet. São Paulo: Editora Juarez de Oliveira, 2005.

LÔBO, Paulo. Direito civil: contratos. São Paulo: Saraiva, 2011.

MARQUES, Claudia Lima. Comentários ao Código de Defesa do Consumidor. 2. ed. São Paulo: Revista dos Tribunais, 2006.

MARQUES, Claudia Lima. Contratos no Código de Defesa do Consumidor: o novo regime das relações contratuais. Biblioteca de Direito do Consumidor, v. 1. 3. ed., ver. atual. e amp. São Paulo: Revista dos Tribunais, 1998. 
MARQUES, Claudia Lima; MIRAGEM, Bruno. O Novo Direito Privado e a Proteção dos Vulneráveis. São Paulo: Ed. RT, 2012.

MARQUES, Gil da Costa; CRESPO, Marcelo Xavier de Freitas. Um panorama sobre a sociedade de informação: o cloud computing e alguns aspectos jurídicos no ambiente digital. In: MENDES, Gilmar Ferreira; SARLET, Ingo Wolfgang; COELHO, Alexandre Zavaglia P. Direito, inovação e tecnologia. São Paulo: Saraiva, 2015.

MARTINS-COSTA, J. A boa-fé no direito privado: sistema e tópica no processo obrigacional. 1. ed. 2. tir. - São Paulo: Editora Revista dos Tribunais, 2000.

MELO, Liana Holanda de. Responsabilidade civil nas relações de consumo. In: Âmbito Jurídico, Rio Grande, XIII, n. 80, set 2010. Disponível em: <https://goo.gl/5oifqy>. Acesso em: 24 ago. 2016.

MENDES, Laura Schertel. A vulnerabilidade do consumidor quanto ao tratamento de dados pessoais. In: Revista de Direito do Consumidor, coord. Claudia Lima Marques, ano 24, vol. 102, nov.-dez., 2015.

MENKEN, Ivanka. The complete cornerstone guide to cloud computing: Best Practices. Australia: Emereo, 2008.

O DROPBOX funciona do seu jeito. Dropbox. Disponível em: <https://goo.gl/Cvj8p>. Acesso em: 9 mar. 2016.

ONEDRIVE, faça mais de qualquer lugar. Disponível em: <https://goo.gl/opD61k>. Acesso em: 9 mar. 2016.

PAESANI, Liliana. Direito e Internet: liberdade de informação, privacidade e responsabilidade civil. 3. ed. São Paulo: Atlas, 2006.

RELVAS, Marcos. Comércio eletrônico: aspectos contratuais da relação de consumo. Curitiba: Juruá, 2005.

SHAW, Thomas J. Cloud computing for lawyers and executives: A global approach. 2. ed. Chicago: American Bar Association, 2013.

SILVA, Luciana Vasco da; FINKELSTEIN; Maria Eugênia. A necessidade de regulação legislativa para utilização do serviço de computação em nuvem. Revista Thesis Juris, São Paulo, v. 3, n. 2, p. 504-522, jul./dez. 2014. Disponível em: <https://goo.gl/kcRncW>. Acesso em: 16 nov. 2017.

TEIXEIRA, Tarcísio. Responsabilidade civil no comércio eletrônico: a livre-iniciativa e a defesa do consumidor. In: DE LUCCA, Newton; SIMÃO FILHO, Adalberto; LIMA, Cíntia Rosa Pereira de (coords.). Direito \& Internet III - Tomo II: Marco Civil da Internet (Lei n 12.965/2014). São Paulo: Quartier Latin, 2015.

TERMOS de serviço do Dropbox. Dropbox. 04 nov. 2015. Disponível em: <https://goo.gl/0tpG8>. Acesso em: 7 mar. 2016. 
VELTE, Anthony T.; VELTE, Toby J.; ELSENPETER, Robert. Cloud computing: computação em nuvem: uma abordagem prática. Tradução de Gabriela Mei. Rio de Janeiro: Alta Books, 2012.

VIGGIANI, Tatiana Sornas; VELLASCO, Welton Rubens Volpe. Aspectos contratuais na contratação de serviços de computação em nuvem. Págs. 421-442. XXIII Congresso Nacional CONPEDI/UFPB: a humanização do direito e a horizontalização da justiça no século XXI. Nov. 2014. Disponível em: <https://goo.gl/MXz8L6>. Acesso em: 14 mar. 2016.

Rosane Leal da Silva

Graduada em Direito pela Universidade da Região da Campanha, Mestre em Integração Latino-Americana pela Universidade Federal de Santa Maria - UFSM - e Doutora em Direito pela Universidade Federal de Santa Catarina. Professora Adjunta na UFSM, nos cursos de Graduação e Mestrado em Direito.E-mail: rolealdasilva@gmail.com

Rafaela Bolson Dalla Favera Mestre em direito pela UFSM. Integrante permanente, desde 2015, do Núcleo de Direito Informacional - NUDI - da UFSM. Advogada. E-mail: rafaeladallafavera@hotmail.com

Olívia Martins de Quadros Olmos Advogada. Revisora de textos da Universidade Franciscana - UFN. Graduada em Letras, Especialista em Língua Portuguesa e Mestre em Letras pela UFSM. Bacharel em Direito pelo Centro Universitário Franciscano.E-mail: oliolmos@yahoo.com.br 